\title{
A rare case of repeated expulsions of a giant cervical fibroid per vaginum followed by delivery of near term babies in two consecutive pregnancies
}

\author{
Vaibhav Kanti ${ }^{1}$, Pragati Mishra ${ }^{1}$, Vandana Gupta ${ }^{1}$, \\ Soniya Vishwakarma ${ }^{1}$, Kalpana Kumari ${ }^{1}$, Pinki Pandey ${ }^{2}$
}

\author{
${ }^{1}$ Department of Obstetrics \& Gynaecology, Uttar Pradesh Rural Institute of Medical Sciences, Saifai, Etawah-206130, \\ U.P., India \\ ${ }^{2}$ Department of Pathology, Uttar Pradesh Rural Institute of Medical Sciences, Saifai, Etawah-206130, U.P., India
}

Received: 15 June 2014

Accepted: 1 July 2014

*Correspondence:

Dr. Vaibhav Kanti,

E-mail: vaibkanti13@gmail.com

(C) 2014 Kanti V et al. This is an open-access article distributed under the terms of the Creative Commons Attribution Non-Commercial License, which permits unrestricted non-commercial use, distribution, and reproduction in any medium, provided the original work is properly cited.

\begin{abstract}
Huge cervical fibroid polyp with red degeneration, obstructing birth canal might be a night mare for obstetricians. Most of us will plan for a caesarean section but somehow due to lack medical consultation; a patient in rural setup with a huge cervical fibroid, delivered normal in two consecutive pregnancies. This case is unique because no such case has been reported in literature where normal delivery took place twice in the same patient, with such a huge fibroid with red degeneration, obstructing the birth canal.
\end{abstract}

Keywords: Huge cervical fibroid, Pregnancy, Normal delivery

\section{INTRODUCTION}

Cervix is a small opening in uterus. Unlike uterine fibroid, cervical fibroid usually do not effect pregnancy. A cervical fibroid during pregnancy may get enlarged and undergo red degeneration and after puerperium it may shrink to a smaller size. If not removed may again get enlarged in next pregnancy and may cause anaemia, constipation, distension of vagina, spotting, bleeding, backache during antenatal period. During peripartum it may lead to low birth weight, preterm delivery, obstructed labour and various other complications.

We report a similar case where a multigravida with a huge cervical fibroid, delivered normal in two consecutive pregnancies, without any postpartum complications.

\section{CASE REPORT}

A 30-years-old G4P3L3 at 36 weeks of gestational age, with severe anemia was referred to us with early labour pains and some soft mass distending the whole of vagina.

On abdominal examination, the fundal height was 34 weeks, fetal heart rate was in midline 158 per minute, head was engaged $2 / 5^{\text {th }}$ palpable. During the course of abdominal examination she expelled a huge reddish mass per vaginum. The mass was pulled aside and per vaginum examination was done, os was 7-8 cm dilated, effacement was $80 \%$, head was at +2 station. She delivered her fourth baby as female of weight $2.5 \mathrm{~kg}$ without any complications.

The mass was inspected and palpated and was found to be arising from anterolateral lip of cervix. Mass was 
removed using a pair of Kocher's clamps and sent for histopathological examination.

She had history of a similar type of delivery one and a half years back.

According to the patient, during the course of her third pregnancy she noticed a progressive growth (upto a fist size), in her vagina. She was able to reduce the mass with her hand. She delivered her third baby at home without any complication.

After the delivery the fibroid got shrunk upto a tennis ball size, but complaints like discharge, off and on spotting, distension of vagina and dyspareunia persisted. There was no complain of constipation or difficulty in defecation either before or after delivery. During the period of lactational amenorrhoea, she conceived for the fourth time and at 7 months of this pregnancy, again noticed the progressive growth in the mass, off and on spotting, dyspareunia, vaginal distension, backache, difficulty in micturition, simulating her previous (third) pregnancy but this time she had history of constipation. The patient had never visited any practitioner for her complaints.

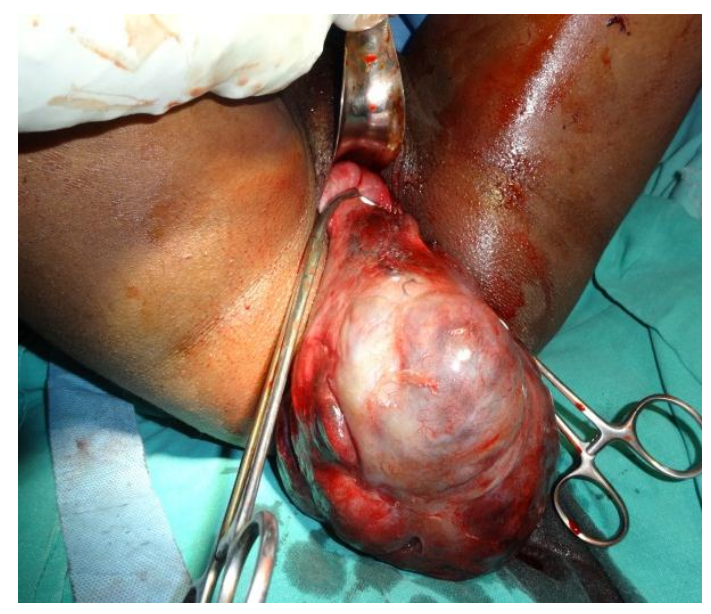

Figure 1: Cervical fibroid removed with a pair Kocher's clamp.

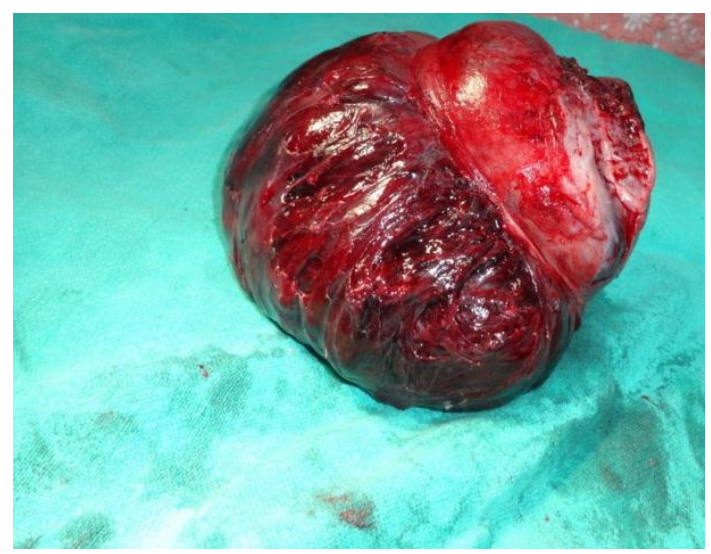

Figure 2: Gross appearance of fibroid.

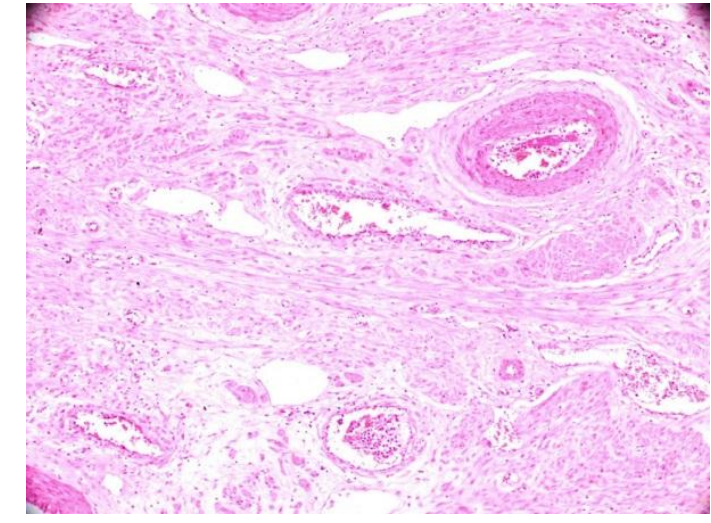

Figure 3: Photo micrograph showing numerous thick walled blood vessels with micro-thrombi, areas of haemorrhage and interlacing bundles of smooth muscle cells (H\&E, x100).

\section{DISCUSSION}

Cervix is the canal through which baby passes during partuation. Cervix consists of involuntary muscles. Cervical fibroids may form during pregnancy and may get enlarged to huge size, distending vagina, obstructing birth canal and can lead to several problems such as anaemia, during antenatal period and obstructed labour during postnatal period. Various types of huge cervical fibroids have been reported - incarcerated procedentia due to cervical fibroid, ${ }^{2}$ huge cervical fibroid in 45 years patient presenting as gynaecological case, ${ }^{3}$ cervical fibroids in adolescence ${ }^{4}$ group, but there is no published case with such a huge cervical fibroid during two consecutive pregnancies, showing red degeneration.

\section{CONCLUSION}

A cervical fibroid during pregnancy may get enlarged and undergo red degeneration and after puerperium it may shrink to a smaller size. If not removed may again get enlarged in next pregnancy and may lead to anaemia, low birth weight, preterm delivery, obstructed labour and various other complications.

Patients even with such huge cervical fibroid may deliver normal.

Funding: No funding sources Conflict of interest: None declared Ethical approval: Not required

\section{REFERENCES}

1. Basnet N, Banerjee B, Badani U, Tiwari A, Raina A, Pokharel H, Yadav, Agarwal A, Chhetri S. An unusual presentation of huge cervical fibroid. Kathmandu Univ Med J. 2005;3(10):173-4.

2. Suneja A, Taneja A, Guleria K, Yadav P, Aggarwal $\mathrm{N}$. Incarcerated procidentia due to cervical fibroid: 
an unusual presentation. Aust NZ J Obstet Gynaecol. 2003;43:252-3.

3. Saini Vandana, Gupta Mamta. A giant sized cervical fibroid: resembling en caul birth. Indian J Basic Applied Med Res. 2013 Sep;2(8):1103-5.

4. Amesse LS, Taneja A, Broxson E, Pfaff-Amesse T. Protruding giant cervical polyp in a young adolescent with a previous rhabdomyosarcoma. J Paediatr Adolesc Gynaecol. 2002 Dec;15(5):271-7.

DOI: $10.5455 / 2320-1770 . i j r \operatorname{cog} 20140926$

Cite this article as: Kanti V, Mishra P, Gupta V, Vishwakarma S, Kumari K, Pandey P. A rare case of repeated expulsions of a giant cervical fibroid per vaginum followed by delivery of near term babies in two consecutive pregnancies. Int J Reprod Contracept Obstet Gynecol 2014;3:790-2. 